\title{
The J-Curve Association Between Blood Pressure and Mortality in Stroke Survivors
}

\author{
Ting Yin' \\ lokfai Cheang' \\ Xu Zhu' \\ Shengen Liao' \\ Haifeng Zhang ${ }^{2}$ \\ Xinli $\mathrm{Li}^{1}$ \\ 'Department of Cardiology, The First \\ Affiliated Hospital of Nanjing Medical \\ University, Jiangsu Province Hospital, \\ Nanjing, 2 10029, People's Republic of \\ China; ${ }^{2}$ Department of Cardiology, The \\ Affiliated Suzhou Hospital of Nanjing \\ Medical University, Suzhou Municipal \\ Hospital, Gusu School, Nanjing Medical \\ University, Suzhou, 215002, People's \\ Republic of China
}

Correspondence: Haifeng Zhang Department of Cardiology, The Affiliated Suzhou Hospital of Nanjing Medical University, Suzhou Municipal Hospital, Gusu School, Nanjing Medical University, Suzhou, 215002, People's Republic of China

Email haifeng_zhang@163.com

Shengen Liao

Department of Cardiology, The First Affiliated Hospital of Nanjing Medical University, Jiangsu Province Hospital,

Nanjing, 210029, People's Republic of China

Email shengenliao@I63.com
Purpose: The optimal blood pressure (BP) targets in terms of mortality risk after stroke remain unclear. This study aimed to assess the relationship between BP and mortality in stroke survivors.

Patients and Methods: We included 1696 participants with self-reported history of stroke aged 18 years and older from the National Health and Nutrition Examination Survey (NHANES) 1999-2014 and NHANES III with public-use linked mortality files from 2015. Baseline systolic BP (SBP) and diastolic BP (DBP) levels were obtained by taking the average of 3 measures. Cox proportional hazard models and restricted cubic splines were conducted to explore the relationship between BP and all-cause mortality.

Results: During a median follow-up period of 5.6 years, 888 deaths occurred. After fully adjusting for confounding factors, SBP displayed a J-curve relationship (nadir $135 \mathrm{~mm} \mathrm{Hg}$ ), while DBP exhibited a reverse J-curve relationship (nadir $73 \mathrm{~mm} \mathrm{Hg}$ ) with the risk of allcause mortality. However, the J-curve or reverse J-curve pattern between blood pressure and mortality appeared to be limited to individuals with an age $>65$ years, identifying a nadir of SBP/DBP of 142/73 mm Hg. The risk of mortality followed a linear relationship for SBP and DBP in stroke survivors aged $\leq 65$ years, with risks increasing with higher SBP and lower DBP.

Conclusion: In this cross-sectional study that used national survey data, these data suggest a strong J-curve or reverse J-curve relationship between blood pressure and risk of all-cause mortality, whereas the pattern appears to be limited to individuals with an age $>65$ years, with a nadir at $142 / 73 \mathrm{mmHg}$. However, missing data on stroke type and stroke treatment limits the generalizability. Future prospective studies are needed to determine preferential blood pressure target in patients after stroke.

Keywords: blood pressure, J-curve, stroke, age, mortality

\section{Introduction}

Stroke is one of the major causes of mortality and disability worldwide. ${ }^{1}$ Elevated blood pressure (BP), smoking, obesity, diet quality, physical activity, and alcohol intake are recognized as modifiable risk factors for stroke, ${ }^{2,3}$ and elevated BP is the most relevant and a modifiable risk factor for stroke. ${ }^{4}$ Evidence from randomized controlled trials supports the use of antihypertensive treatment in the secondary prevention of stroke. ${ }^{5}$ However, most of the randomized controlled trials of secondary stroke prevention did not specifically evaluate the association between the extent of BP reduction and mortality in patients with stroke; thus, the optimal BP targets after stroke remain uncertain. 
Although current guidelines recommend a target systolic BP (SBP) $<130 \mathrm{mmHg}^{6}$ or $120-130 \mathrm{mmHg}^{7}$ for the secondary prevention of stroke, the relationship between BP levels and outcomes in stroke patients in previous studies were inconsistent. A randomized clinical trial and meta-analysis suggest an aim of intensive BP lowering with a target BP less than 130/80 mmHg for the secondary prevention of stroke recurrence. ${ }^{5}$ While another meta regression analysis showed that the extent of both SBP and diastolic BP (DBP) reduction is linearly associated with the magnitude of risk reduction in recurrent cerebrovascular and cardiovascular events. ${ }^{8}$ However, low BP levels have also been associated with a higher risk for adverse events in some post hoc analyses of randomized controlled trials $^{9,10}$ and observational studies. ${ }^{11,12}$ The post hoc observational analysis of the Prevention Regimen for Effectively Avoiding Second Strokes (PROFESS) trial showed that among individuals with a recent non-cardioembolic ischemic stroke, risk of further vascular events was significantly higher for those patients with a mean SBP level below $120 \mathrm{mmHg}$ than for those patients with a level between $130 \mathrm{mmHg}$ and 139 $\mathrm{mmHg}$, even after adjusting for major confounders. ${ }^{10}$ In a large observational study including 2397 ischemic stroke (IS) or transient ischemic attack (TIA) patients, both low and high SBP levels were associated with increased risk of poor clinical outcomes, suggesting that SBP 115-134 mmHg could be the optimal range for IS/TIA patients. ${ }^{11}$

Previous studies have reported the potential J-curve phenomenon between SBP and mortality. ${ }^{13,14}$ However, the ideal SBP is controversial, and few studies have investigated the association between DBP and mortality in stroke survivors. Our aim was to study the association between systolic and diastolic BP levels and mortality in a nationally representative sample of US adults with stroke from the National Health and Nutrition Examination Survey (NHANES).

\section{Materials and Methods}

\section{Patients}

The data were obtained from NHANES 1999-2014 and NHANES III, two nationally representative

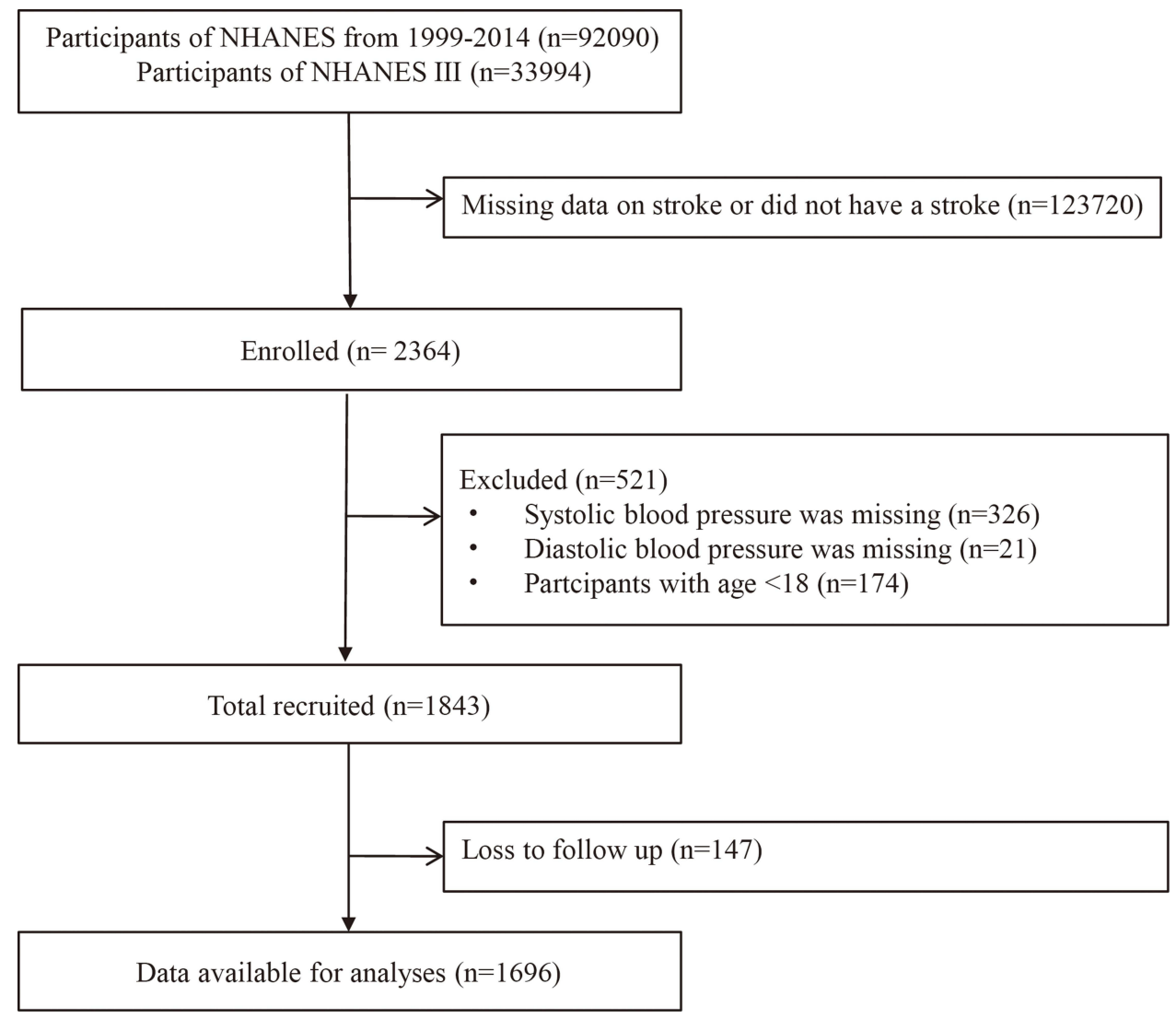

Figure I Study flow chart. 
Table I Characteristics of the Study Population by Systolic Blood Pressure Categories

\begin{tabular}{|c|c|c|c|c|c|c|c|}
\hline Variable & $\begin{array}{l}\text { Total } \\
(n=1696)\end{array}$ & $\begin{array}{l}\text { SBP } \leq 100 \\
\mathrm{mmHg} \\
(\mathrm{n}=59)\end{array}$ & $\begin{array}{l}S B P>100 \\
\text { to } \leq 120 \mathrm{mmHg} \\
(n=36 I)\end{array}$ & $\begin{array}{l}S B P>120 \text { to } \\
\leq 140 \mathrm{mmHg} \\
(n=608)\end{array}$ & $\begin{array}{l}S B P>140 \text { to } \\
\leq 160 \mathrm{mmHg} \\
(n=400)\end{array}$ & $\begin{array}{l}\text { SBP > } 160 \\
\mathrm{mmHg} \\
(n=268)\end{array}$ & $P$ value \\
\hline Age, years & $68.3(13.6)$ & $61.7(16.0)$ & $62.3(16.1)$ & $68.4(13.2)$ & $71.9(10.6)$ & $72.2(10.6)$ & $<0.001$ \\
\hline Male, \% & 843 (49.7\%) & $32(54.2 \%)$ & 177 (49.0\%) & $319(52.5 \%)$ & 198 (49.5\%) & 117 (43.7\%) & 0.176 \\
\hline Race/ethnicity, \% & & & & & & & 0.537 \\
\hline Non-Hispanic White & 936 (55.2\%) & $31(52.5 \%)$ & 197 (54.6\%) & 355 (58.4\%) & $212(53.0 \%)$ & | 4 | (52.6\%) & \\
\hline Non-Hispanic Black & 440 (25.9\%) & 20 (33.9\%) & $92(25.5 \%)$ & 144 (23.7\%) & $108(27.0 \%)$ & $76(28.4 \%)$ & \\
\hline Other race & $320(18.9 \%)$ & $8(13.6 \%)$ & 72 (19.9\%) & $109(17.9 \%)$ & 80 (20.0\%) & 51 (19.0\%) & \\
\hline Diabetes mellitus, \% & $492(29.0 \%)$ & $13(22.0 \%)$ & $96(26.6 \%)$ & $187(30.8 \%)$ & $112(28.0 \%)$ & $84(31.3 \%)$ & 0.376 \\
\hline Hypertension, \% & 1238 (73.0\%) & $36(61.0 \%)$ & $225(62.3 \%)$ & $428(70.4 \%)$ & 322 (80.5\%) & 227 (84.7\%) & $<0.001$ \\
\hline Anti-hypertensive treatment, \% & 1127 (66.5\%) & $35(59.3 \%)$ & $207(57.3 \%)$ & $392(64.5 \%)$ & 287 (71.8\%) & $206(76.9 \%)$ & $<0.001$ \\
\hline Congestive heart failure, $\%$ & $312(18.4 \%)$ & $19(32.2 \%)$ & $53(14.7 \%)$ & III (I8.3\%) & $72(18.0 \%)$ & 57 (21.3\%) & 0.015 \\
\hline Smoker, \% & 1015 (59.8\%) & $37(62.7 \%)$ & $226(62.6 \%)$ & $365(60.0 \%)$ & $232(58.0 \%)$ & 155 (57.8\%) & 0.668 \\
\hline Alcohol user, \% & I20I (70.8\%) & $43(72.9 \%)$ & $272(75.3 \%)$ & $417(68.6 \%)$ & $289(72.2 \%)$ & $180(67.2 \%)$ & 0.121 \\
\hline Pulse, beats/min & $75.4(15.8)$ & $72.8(12.3)$ & $72.5(12.3)$ & $72.7(12.2)$ & $71.1(13.5)$ & $72.5(12.6)$ & 0.162 \\
\hline Body mass index, $\mathrm{kg} / \mathrm{m}^{2}$ & $28.8(6.54)$ & $28.8(7.05)$ & $29.0(6.64)$ & $29.0(6.83)$ & $28.6(6.45)$ & $28.2(5.68)$ & $<0.001$ \\
\hline Waist circumference, $\mathrm{cm}$ & $102(15.0)$ & $103(19.1)$ & $102(15.4)$ & $103(15.3)$ & $101(14.1)$ & $100(14.0)$ & $<0.001$ \\
\hline Stroke length, year & $7.76(8.25)$ & $5.90(6.74)$ & $7.52(7.69)$ & $7.97(8.87)$ & $8.58(8.66)$ & $6.81(7.00)$ & 0.088 \\
\hline
\end{tabular}

Notes: Data are presented as mean (SD), or $\mathrm{n}(\%)$.

Abbreviation: SBP, systolic blood pressure.

surveys in the United States that are publicly available online (https://www.cdc.gov/nchs/nhanes/index.htm). We identified a total of 126,084 participants from the 19992014 NHANES campaigns and NHANES III. Stroke was obtained by participant report that a physician or other health professional had previously diagnosed that particular condition. The present study focused on stroke survivors who answered yes to the question: "Has a doctor or other health professional ever told you that you had a stroke?" ( $\mathrm{n}=123,720)$. We excluded participants with missing data on SBP $(n=326)$ or DBP $(n=21)$, an age $<18$ years $(n=174)$ or missing mortality data $(n=147)$. Finally, 1696 participants were available for the analysis (Figure 1). NHANES was approved by the National Center for Health Statistics research ethics review board, and each participant provided written informed consent. All examinations were conducted in a mobile examination center.

\section{BP Assessment}

$\mathrm{BP}$ readings were measured by trained technicians using a mercury sphygmomanometer with cuffs suitable for the size of participants' arms. After the patients rested quietly for at least 5 minutes in the mobile test center, up to 3 consecutive readings were taken for each patient on the same arm. A fourth measurement was performed if required. Detailed protocols are available online (https:// www.cdc.gov/nchs/data/nhanes/nhanes_13_14/Phys Exam Manual 2013.pdf). In our study, we calculated the average of up to 3 brachial systolic and diastolic BP readings for each subject. We categorized SBP into $20 \mathrm{mmHg}$ increments $(\mathrm{SBP} \leq 100 \mathrm{mmHg}, \mathrm{SBP}>100 \mathrm{mmHg}$ to $\leq 120$ $\mathrm{mmHg}, \quad \mathrm{SBP}>120 \mathrm{mmHg}$ to $\leq 140 \mathrm{mmHg}, \quad \mathrm{SBP}>140$ $\mathrm{mmHg}$ to $\leq 160 \mathrm{mmHg}, \mathrm{SBP}>160 \mathrm{mmHg}$ ) and DBP into $10 \mathrm{mmHg}$ increments $(\mathrm{DBP} \leq 60 \mathrm{mmHg}, \mathrm{DBP}>60 \mathrm{mmHg}$ to $\leq 70 \mathrm{mmHg}$, DBP $>70 \mathrm{mmHg}$ to $\leq 80 \mathrm{mmHg}$, DBP $>80$ $\mathrm{mmHg}$ to $\leq 90 \mathrm{mmHg}, \mathrm{DBP}>90 \mathrm{mmHg}$ ).

\section{Covariates and Outcomes}

Additional data on demographic characteristics, including age, race (non-Hispanic white, non-Hispanic black, and others), and sex, were obtained from self-reports. Smokers were defined as those who reported smoking more than 100 cigarettes during their lifetime. ${ }^{15}$ Alcohol users were defined as those who had at least 12 drinks in the last 12 months. ${ }^{16}$ A previous history of hypertension, diabetes, and congestive heart failure was also determined from self-reports. Pulse, body mass index (BMI), and waist circumference were also measured. All-cause mortality was the primary outcome. Cardiovascular and cerebrovascular mortality 
Table 2 Characteristics of the Study Population by Diastolic Blood Pressure Categories

\begin{tabular}{|c|c|c|c|c|c|c|c|}
\hline Variable & $\begin{array}{l}\text { Total } \\
(n=1696)\end{array}$ & $\begin{array}{l}\mathrm{DBP} \leq 60 \\
\mathrm{mmHg} \\
(\mathrm{n}=374)\end{array}$ & $\begin{array}{l}\text { DBP }>60 \text { to } \\
\leq 70 \mathrm{mmHg} \\
(n=439)\end{array}$ & $\begin{array}{l}\text { DBP }>70 \text { to } \\
\leq 80 \mathrm{mmHg} \\
(n=477)\end{array}$ & $\begin{array}{l}\text { DBP }>80 \text { to } \\
\leq 90 \mathrm{mmHg} \\
(\mathrm{n}=277)\end{array}$ & $\begin{array}{l}\mathrm{DBP}>90 \\
\mathrm{mmHg} \\
(\mathrm{n}=129)\end{array}$ & $P$ value \\
\hline Age, years & $68.3(13.6)$ & $72.9(10.9)$ & $69.7(13.7)$ & $66.7(14.6)$ & $65.2(13.5)$ & $63.1(12.8)$ & $<0.001$ \\
\hline Male, \% & $843(49.7 \%)$ & I 82 (48.7\%) & 206 (46.9\%) & 234 (49.1\%) & 147 (53.1\%) & $74(57.4 \%)$ & 0.208 \\
\hline $\begin{array}{l}\text { Race/ethnicity, \% } \\
\text { Non-Hispanic White } \\
\text { Non-Hispanic Black } \\
\text { Other race }\end{array}$ & $\begin{array}{l}936(55.2 \%) \\
440(25.9 \%) \\
320(18.9 \%)\end{array}$ & $\begin{array}{l}229(61.2 \%) \\
81(21.7 \%) \\
64(17.1 \%)\end{array}$ & $\begin{array}{l}257(58.5 \%) \\
93(21.2 \%) \\
89(20.3 \%)\end{array}$ & $\begin{array}{l}267(56.0 \%) \\
124(26.0 \%) \\
86(18.0 \%)\end{array}$ & $\begin{array}{l}139(50.2 \%) \\
84(30.3 \%) \\
54(19.5 \%)\end{array}$ & $\begin{array}{l}44(34.1 \%) \\
58(45.0 \%) \\
27(20.9 \%)\end{array}$ & $<0.001$ \\
\hline Diabetes mellitus, \% & $492(29.0 \%)$ & 138 (36.9\%) & $136(31.0 \%)$ & II 6 (24.3\%) & $74(26.7 \%)$ & $28(21.7 \%)$ & $<0.001$ \\
\hline Hypertension, \% & 1238 (73.0\%) & $28 \mid(75.1 \%)$ & 305 (69.5\%) & $323(67.7 \%)$ & $217(78.3 \%)$ & $112(86.8 \%)$ & $<0.001$ \\
\hline $\begin{array}{l}\text { Anti-hypertensive } \\
\text { treatment, } \%\end{array}$ & I I 27 (66.5\%) & $27 \mid(72.5 \%)$ & 281 (64.0\%) & $288(60.4 \%)$ & 191 (69.0\%) & $96(74.4 \%)$ & $<0.001$ \\
\hline $\begin{array}{l}\text { Congestive heart } \\
\text { failure, } \%\end{array}$ & $312(18.4 \%)$ & 73 (19.5\%) & $101(23.0 \%)$ & 75 (I5.7\%) & $40(14.4 \%)$ & $23(17.8 \%)$ & 0.020 \\
\hline Smoker, \% & 1015 (59.8\%) & $222(59.4 \%)$ & $26 \mid(59.5 \%)$ & $28 \mid(58.9 \%)$ & 169 (61.0\%) & $82(63.6 \%)$ & 0.888 \\
\hline Alcohol user, \% & $120 \mid$ (70.8\%) & $252(67.4 \%)$ & 307 (69.9\%) & 338 (70.9\%) & 202 (72.9\%) & $102(79.1 \%)$ & 0.128 \\
\hline Pulse, beats/min & $72.5(12.6)$ & $70.1(12.3)$ & $71.6(11.8)$ & $72.5(12.2)$ & $75.1(14.4)$ & $76.7(12.1)$ & $<0.001$ \\
\hline $\begin{array}{l}\text { Body mass index, } \mathrm{kg} / \\
\mathrm{m}^{2}\end{array}$ & $28.8(6.54)$ & $28.6(6.32)$ & $28.2(6.44)$ & $29.0(6.60)$ & $29.3(6.86)$ & $29.1(6.50)$ & 0.201 \\
\hline $\begin{array}{l}\text { Waist } \\
\text { circumference, cm }\end{array}$ & $102(15.0)$ & $102(14.6)$ & $100(14.8)$ & $102(15.2)$ & $102(15.9)$ & $102(14.8)$ & 0.284 \\
\hline Stroke length, year & $7.76(8.25)$ & $8.16(8.52)$ & 7.64 (8.49) & $7.64(8.00)$ & $7.96(8.37)$ & $7.05(7.34)$ & 0.773 \\
\hline
\end{tabular}

Notes: Data are presented as mean (SD), or $\mathrm{n}(\%)$.

Abbreviation: DBP, diastolic blood pressure.

was considered as the secondary outcome. Public-use linked mortality files are available online.

\section{Statistical Analysis}

Baseline demographic and health characteristics were compared across SBP or DBP categories using a 1-way analysis of variance model (ANOVA) for continuous variables and chi-square statistics for categorical variables. Kaplan-Meier curves were produced and compared among the SBP or DBP categories of patients by the Log rank test. We evaluated the association between BP categories and all-cause mortality using Cox proportional hazards regression. Variables with statistically significant differences in terms of all-cause mortality $(P<0.05)$ in univariate Cox regression analysis were used to derive the final model. For all-primary and secondary outcomes, we fitted hazard ratios (HRs) for age, sex, and race/ethnicity (Model 1); and age, sex, race/ ethnicity, diabetes mellitus, congestive heart failure, smoking, systolic pressure or diastolic pressure, body mass index, waist circumference, and anti-hypertensive treatment (Model 2), and the results were demonstrated as the corresponding 95\% confidence intervals (CIs). Restricted cubic splines with 3 knots placed at the 10th, 50th and 90th percentiles (the number of knots was selected according to the Akaike information criterion) were generated to examine the fully adjusted nonlinear relationships of BP with mortality, and the tests for nonlinearity were calculated using Wald $\chi^{2}$ tests. $^{17}$

Subgroup analyses stratified by age, sex, and BMI were conducted based on Model 2. Multivariable regression models were tested for interaction analysis. We regarded the median value of each SBP or DBP category as a continuous variable in the same model to test for linear trends. All analyses were performed by $\mathrm{R}$ software version 3.6.0 ( $\mathrm{R}$ 

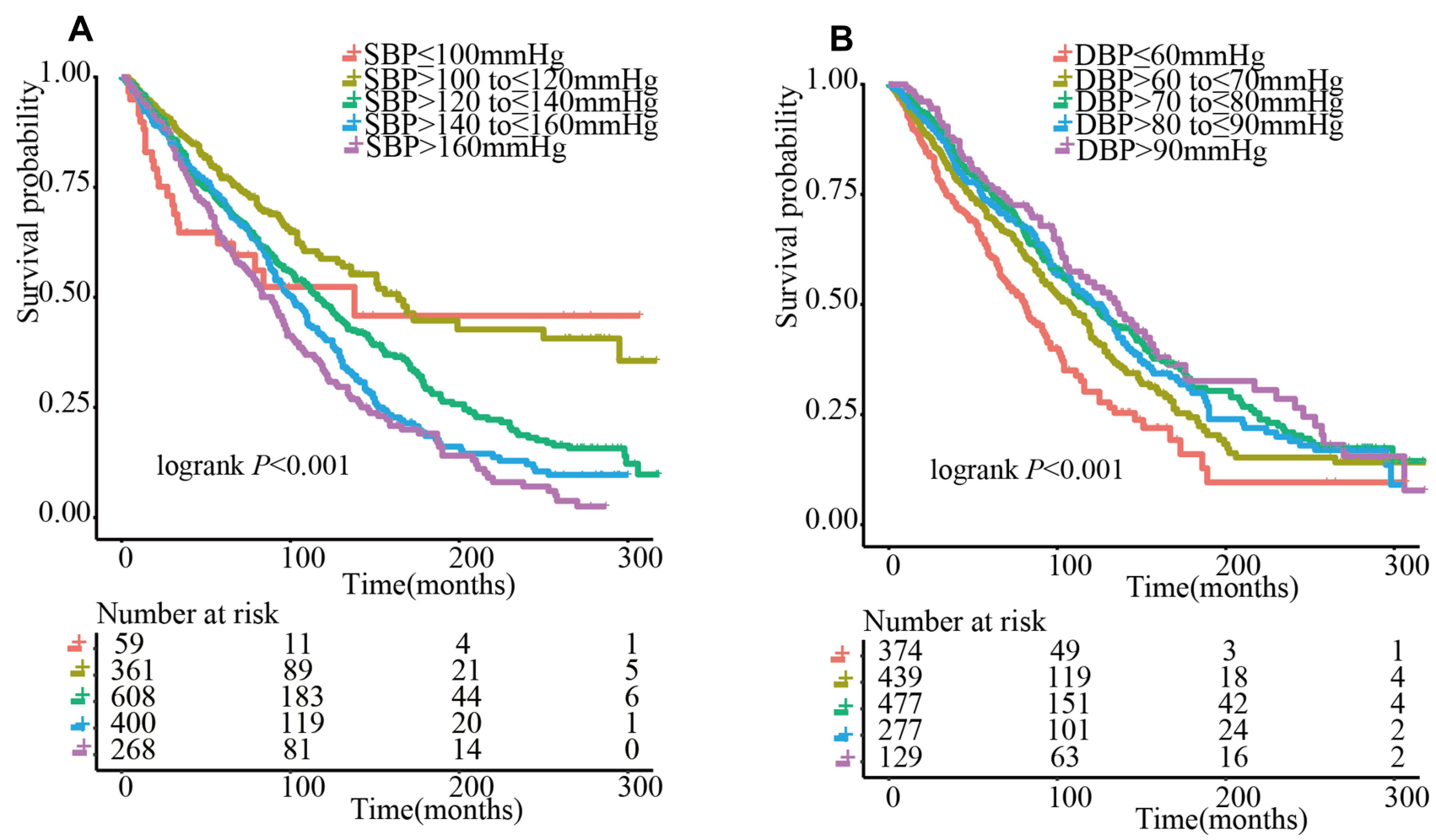

Figure 2 Kaplan-Meier survival curves illustrating the rate of all-cause mortality according to SBP categories (A) and DBP categories (B).

Foundation for Statistical Computing, Vienna, Austria) and Stata 14.0 (Stata Corporation, College Station, TX, USA). A $P$ value $<0.05$ was considered statistically significant.

\section{Results}

\section{Baseline Characteristics}

The baseline characteristics of the patients according to SBP (in $20 \mathrm{mmHg}$ increments) and DBP categories (in 10 $\mathrm{mmHg}$ increments) are listed in Tables 1 and 2, respectively. Adults with higher SBP were older, had higher BMI. In addition, adults with higher DBP were older and had faster pulse rates and a lower likelihood of having a history of diabetes.

\section{BP and Risk of Death}

After a median follow-up of 5.6 years, 888 deaths occurred, of which 316 deaths were due to cardiovascular and cerebrovascular disease. The associations of SBP and DBP categories with mortality are shown in Figure 2. The KaplanMeier curves for the rates of all-cause mortality showed a substantially higher risk of death among stroke patients with increasing SBP categories (Figure 2A, log-rank $P<0.001$ ); however, the rates of all-cause mortality decreased with increasing DBP categories (Figure 2B, log-rank $P<0.001)$. Baseline age, sex, race/ethnicity, diabetes mellitus, congestive heart failure, smoker, systolic pressure or diastolic pressure, body mass index, waist and anti-hypertensive treatment $(P$ values $<0.05)$ were considered as potential risk factors for long-term all-cause mortality in stroke survivors (Table 3). After fully adjusting for potential confounding factors in Model 2, compared with the reference SBP range subgroup (SBP $>120$ to $\leq 140 \mathrm{mmHg}$ ), the only SBP subgroup to retain an increased risk of mortality was that of patients with SBP $\leq 100 \mathrm{mmHg}$ (all-cause mortality: HR 1.71; 95\% CI 1.11-2.64; cardiovascular and cerebrovascular mortality: HR 1.16 ; 95\% CI 0.46-2.93). The risk of all cause death or cardiovascular and cerebrovascular mortality tended to increase above the reference SBP range. Similar trends were also observed in the DBP categories. The rates of allcause mortality also increased below and above the reference DBP range. Compared with the reference DBP range subgroup (DBP $>70$ to $\leq 80 \mathrm{mmHg}$ ), the only DBP subgroup to retain an increased risk of all-cause mortality was that of 
Table 3 Univariate COX Regression Analysis of Predictors for Mortality

\begin{tabular}{|c|c|c|}
\hline & HR (95\% Cl) & $P$ value \\
\hline Age, years & $1.07(1.06,1.08)$ & $<0.001$ \\
\hline Male & $1.39(1.22,1.58)$ & $<0.001$ \\
\hline \multicolumn{3}{|l|}{ Race/ethnicity } \\
\hline Non-Hispanic White & $\mathrm{I} .00$ (ref.) & \\
\hline Non-Hispanic Black & $0.71(0.60,0.83)$ & $<0.001$ \\
\hline Other race & $0.54(0.44,0.65)$ & $<0.001$ \\
\hline Diabetes mellitus & $1.30(1.12,1.50)$ & $<0.001$ \\
\hline Hypertension & $1.12(0.97,1.30)$ & 0.132 \\
\hline Anti-hypertensive treatment & $1.15(1.00,1.32)$ & 0.043 \\
\hline Congestive heart failure & $1.46(1.25,1.71)$ & $<0.001$ \\
\hline Alcohol user & $0.99(0.85, \mathrm{I} .15)$ & 0.862 \\
\hline Smoker & $1.15(1.00,1.31)$ & 0.046 \\
\hline Pulse, beats/min & $1.00(1.00,1.00)$ & 0.092 \\
\hline Body mass index, $\mathrm{kg} / \mathrm{m}^{2}$ & $0.97(0.96,0.98)$ & $<0.001$ \\
\hline Waist circumference, $\mathrm{cm}$ & $1.00(0.99,1.00)$ & 0.039 \\
\hline Systolic blood pressure, mm Hg & $1.01(1.01,1.01)$ & $<0.001$ \\
\hline Diastolic blood pressure, $\mathrm{mm} \mathrm{Hg}$ & $0.99(0.92,0.99)$ & $<0.001$ \\
\hline Stroke length, year & $1.00(1.00,1.01)$ & 0.397 \\
\hline
\end{tabular}

Abbreviations: $\mathrm{HR}$, hazard ratios; $\mathrm{Cl}$, confidence intervals. patients with $\mathrm{DBP} \leq 60 \mathrm{mmHg}$ (HR 1.46; 95\% CI 1.05-1.70) (Table 4).

This nonlinear relationship between BP and adjusted mortality was assessed by restricted cubic splines. Figure 3 illustrates the adjusted HR for mortality along the continuum of SBP and DBP. SBP displayed a J-curve relationship ( $P$ for nonlinearity $=0.010)$, while DBP followed a reverse J-curve relationship $(P$ for nonlinearity $<0.001)$ with the risk of allcause mortality, and the mortality hazard nadir was observed at $135 / 73 \mathrm{mmHg}$. Similar trends were also found in the association between SBP/DBP levels and cardiovascular and cerebrovascular mortality, and the mortality hazard nadir was observed at 131/71 $\mathrm{mmHg}$.

\section{Subgroup Analysis}

Interaction analyses revealed a statistically significant interaction between SBP and age ( $P$ for interaction $<0.001)$ after adjusting for confounding factors (Table 5). However, there was no significant interaction between SBP and sex or obesity status. This J-curve relationship between SBP and mortality persisted in patients aged $>65$ years with a nadir of $142 \mathrm{mmHg}$ ( $P$ for nonlinearity $=0.007$ ) (Figure 4A), and higher SBP was linearly associated with an increased risk of mortality in patients aged $\leq 65$ years (Figure 4C). However, interaction analyses revealed no significant

Table 4 Adjusted Hazard Ratios (95\% Confidence Intervals) for All-Cause Mortality

\begin{tabular}{|c|c|c|c|c|}
\hline & \multicolumn{2}{|c|}{ All Cause Mortality } & \multicolumn{2}{|c|}{ Cardiovascular and Cerebrovascular Mortality } \\
\hline & Model I & Model 2 & Model I & Model 2 \\
\hline & HR $(95 \% \mathrm{CI})$ & HR $(95 \% \mathrm{Cl})$ & HR $(95 \% \mathrm{CI})$ & HR $(95 \% \mathrm{Cl})$ \\
\hline \multicolumn{5}{|l|}{$\mathrm{SBP}(\mathrm{mmHg})$} \\
\hline $\mathrm{SBP} \leq 100 \mathrm{mmHg}$ & $1.70(1.12-2.59)^{*}$ & $1.71(1.11-2.64)^{*}$ & $0.86(0.35-2.11)$ & $1.16(0.46-2.93)$ \\
\hline $\mathrm{SBP}>100$ to $\leq 120 \mathrm{mmHg}$ & $0.92(0.74-1.14)$ & $0.96(0.77-1.19)$ & $0.57(0.38-0.86)^{* *}$ & $0.71(0.47-1.08)$ \\
\hline $\mathrm{SBP}>120$ to $\leq 140 \mathrm{mmHg}$ & I.00(ref.) & I.00(ref.) & I.00(ref.) & I.00(ref.) \\
\hline $\mathrm{SBP}>140$ to $\leq 160 \mathrm{mmHg}$ & $0.99(0.84-1.18)$ & $1.00(0.84-1.19)$ & $0.88(0.66-1.16)$ & $0.86(0.64-1.14)$ \\
\hline $\mathrm{SBP}>160 \mathrm{mmHg}$ & $1.16(0.97-1.39)$ & $1.20(0.99-1.46)$ & $1.14(0.86-1.53)$ & $1.10(0.80-1.50)$ \\
\hline \multicolumn{5}{|l|}{$\mathrm{DBP}(\mathrm{mmHg})$} \\
\hline $\mathrm{DBP} \leq 60 \mathrm{mmHg}$ & $1.36(1.12-1.65)^{* *}$ & $1.42(1.15-1.75)^{* *}$ & $0.98(0.69-1.39)$ & $1.30(0.89-1.89)$ \\
\hline DBP $>60$ to $\leq 70 \mathrm{mmHg}$ & $1.08(0.90-1.30)$ & $1.05(0.87-1.27)$ & $1.05(0.78-1.43)$ & $1.06(0.77-1.44)$ \\
\hline DBP $>70$ to $\leq 80 \mathrm{mmHg}$ & I.00(ref.) & I.00(ref.) & 1.00 (ref.) & I.00(ref.) \\
\hline DBP $>80$ to $\leq 90 \mathrm{mmHg}$ & $1.19(0.98-1.46)$ & $1.17(0.95-1.43)$ & $1.49(1.09-2.04)$ & $1.46(1.05-2.02)^{*}$ \\
\hline $\mathrm{DBP}>90 \mathrm{mmHg}$ & I.I4(0.88-1.48) & $1.06(0.81-1.40)$ & $1.22(0.79-1.87)$ & $1.08(0.68-1.70)$ \\
\hline
\end{tabular}

Notes: Model I was adjusted for nonmodifiable risk factors (age and sex). Model 2 was adjusted for combination of nonmodifiable and modifiable risk factors (age, sex, race/ethnicity, diabetes mellitus, congestive heart failure, smoker, systolic pressure or diastolic pressure, body mass index, waist and anti-hypertensive treatment). $* * P<0.0 \mathrm{I}$, $* P<0.05$.

Abbreviations: SBP, systolic blood pressure; DBP, diastolic blood pressure; HR, hazard ratios; $\mathrm{Cl}$, confidence intervals. 


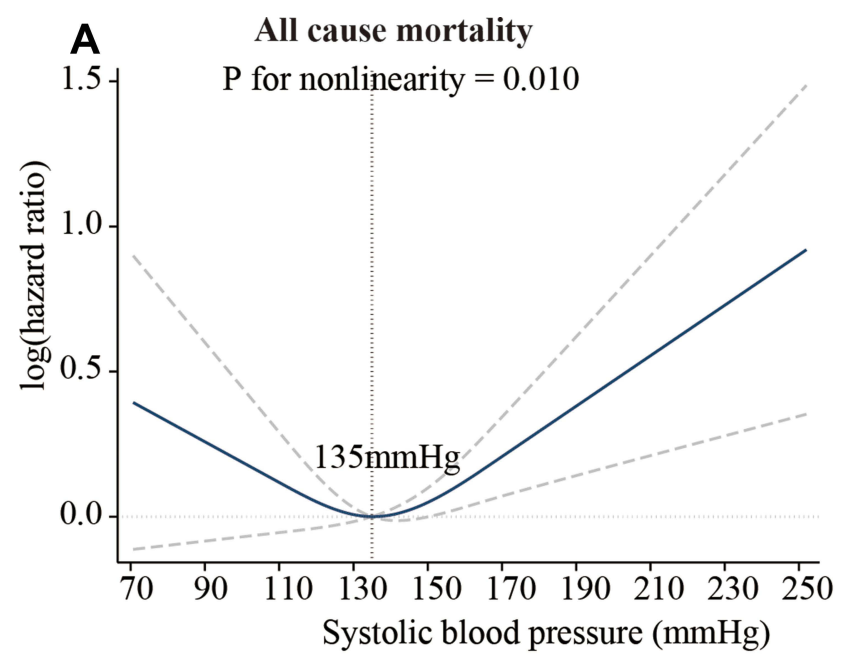

C cardiovascular and cerebrovascular mortality

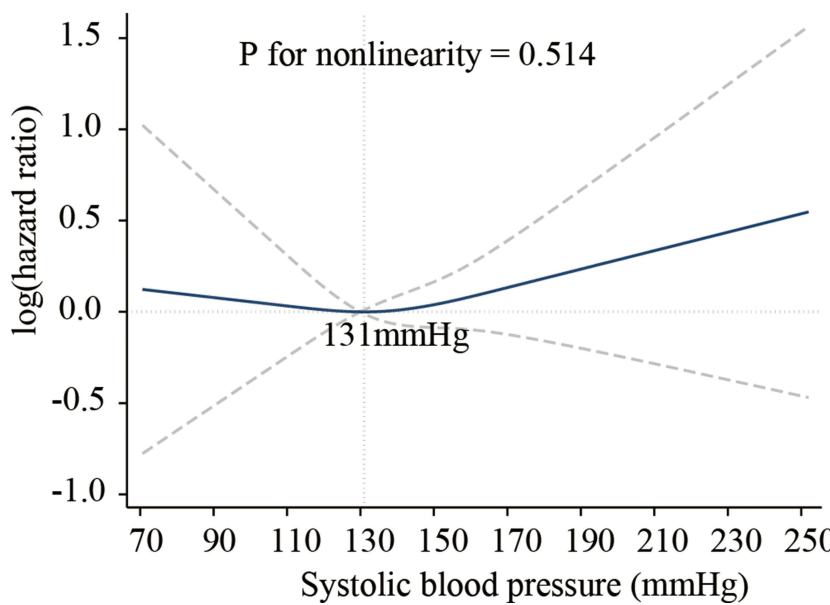

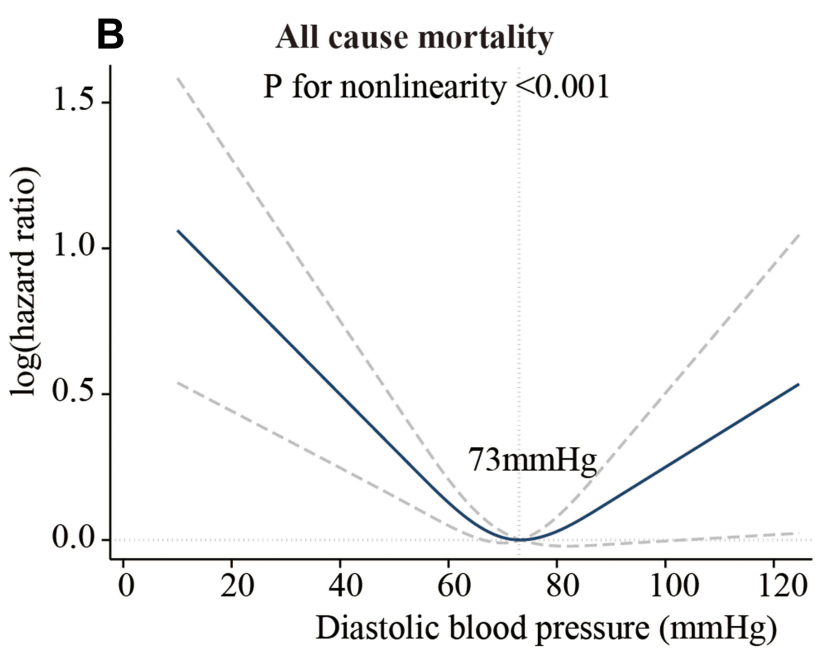

D cardiovascular and cerebrovascular mortality

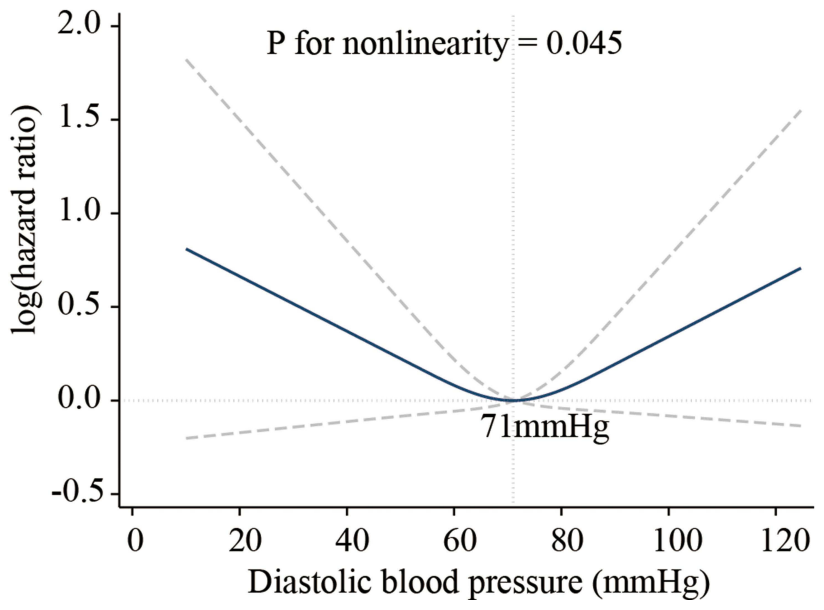

Figure 3 Restricted cubic spline plots of the association between blood pressure and risk of death. (A) SBP: all cause mortality; (B) DBP: all cause mortality; (C) SBP: cardiovascular and cerebrovascular mortality; (D) DBP: cardiovascular and cerebrovascular mortality.

effect between DBP and age, sex or obesity status after adjusting for confounding factors (Table 6). Although the interaction of age with DBP was not significant, agestratified models suggested that the association of DBP with mortality in patients aged $>65$ years followed a reverse J-curve relationship with a nadir at 73 $\mathrm{mmHg}(P$ for nonlinearity=0.004) (Figure 4B), and higher DBP was linearly associated with a decreased risk of mortality in patients aged $\leq 65$ years (Figure 4D).

\section{Discussion}

To our knowledge, this nationally representative cohort study is the first to demonstrate a reverse J-curve relationship between DBP and all-cause mortality in stroke survivors. Results demonstrated that SBP and all-cause mortality showed a J-curve relationship. Lower SBP or DBP portends an increased risk of all-cause mortality. However, the J-curve or reverse J-curve pattern was limited to individuals aged $>65$ years with a nadir of SBP/DBP at $142 / 73 \mathrm{mmHg}$. To the best of our knowledge, this is the first report of an association of the interaction between SBP and age with all-cause mortality in a relatively large selected population of stroke survivors.

Our findings are consistent with previous data reporting the association of all-cause mortality with SBP in adults with self-reported stroke of NHNSE 1998-2004, ${ }^{13}$ and Hypertensive patients with electrocardiographic left ventricular hypertrophy. ${ }^{14}$ Also add 
Table 5 Stratified Associations Between Systolic Blood Pressure and Mortality by Age, Sex and BMI

\begin{tabular}{|c|c|c|c|c|c|c|c|}
\hline & \multirow{2}{*}{\begin{tabular}{|l|}
$\mathrm{SBP} \leq 100 \mathrm{mmHg}$ \\
$\mathrm{HR}(95 \% \mathrm{Cl})$
\end{tabular}} & \multirow{2}{*}{$\begin{array}{l}\text { SBP> } 100 \text { to } \\
\leq 120 \mathrm{mmHg} \\
\mathrm{HR}(95 \% \mathrm{Cl})\end{array}$} & \multirow{2}{*}{$\begin{array}{l}\text { SBP> I } 20 \text { to } \\
\leq 140 \mathrm{mmHg}\end{array}$} & \multirow{2}{*}{$\begin{array}{l}\text { SBP> } 140 \text { to } \\
\leq 160 \mathrm{mmHg} \\
\mathrm{HR}(95 \% \mathrm{Cl})\end{array}$} & \multirow{2}{*}{$\begin{array}{l}\mathrm{SBP}>160 \mathrm{mmHg} \\
\mathrm{HR}(95 \% \mathrm{Cl})\end{array}$} & \multicolumn{2}{|c|}{$P$ value } \\
\hline & & & & & & Trend & Interaction \\
\hline \multicolumn{8}{|l|}{ Age } \\
\hline$\leq 65, N=602$ & $0.66(0.27-1.62)$ & $0.73(0.47-1.15)$ & I.00(ref.) & $1.56(1.02-2.40)$ & $2.54(1.62-3.98)^{* * * *}$ & $<0.001$ & $<0.001$ \\
\hline$>65, N=1094$ & $2.44(1.48-4.00)^{* *}$ & $0.92(0.72-1.19)$ & I.00(ref.) & $1.01(0.84-1.22)$ & $1.21(0.98-1.50)$ & 0.303 & \\
\hline \multicolumn{8}{|l|}{ Sex } \\
\hline Male, $\mathrm{N}=843$ & $1.34(0.79-2.30)$ & $1.05(0.79-1.40)$ & 1.00 (ref.) & $0.99(0.79-1.40)$ & $1.21(0.91-1.60)$ & 0.658 & $0.44 I$ \\
\hline Female, $N=853$ & $3.86(1.81-8.22)^{* * *}$ & $0.85(0.60-1.20)$ & I.00(ref.) & $1.01(0.78-1.30)$ & I.I7(0.89-I.54) & 0.298 & \\
\hline \multicolumn{8}{|l|}{ BMI } \\
\hline$\geq 30, N=588$ & $1.22(0.54-2.78)$ & $1.13(0.75-1.70)$ & I.00(ref.) & $1.01(0.71-1.42)$ & $1.54(1.04-2.29)^{*}$ & 0.242 & 0.923 \\
\hline$<30, N=1108$ & $1.93(1.15-3.24)^{*}$ & $0.92(0.7|-| .20)$ & I.00(ref.) & $1.04(0.85-1.26)$ & $1.14(0.91-1.43)$ & 0.407 & \\
\hline
\end{tabular}

Notes: Analyses was adjusted for age, sex, race/ethnicity, diabetes mellitus, congestive heart failure, smoker, antihypertensive treatment, systolic pressure or diastolic pressure, body mass index and waist when they were not the strata variables. $* * * P<0.001, * * P<0.01, * P<0.05$.

Abbreviations: SBP, systolic blood pressure; BMI, Body mass index; HR, hazard ratios; $\mathrm{Cl}$, confidence intervals.
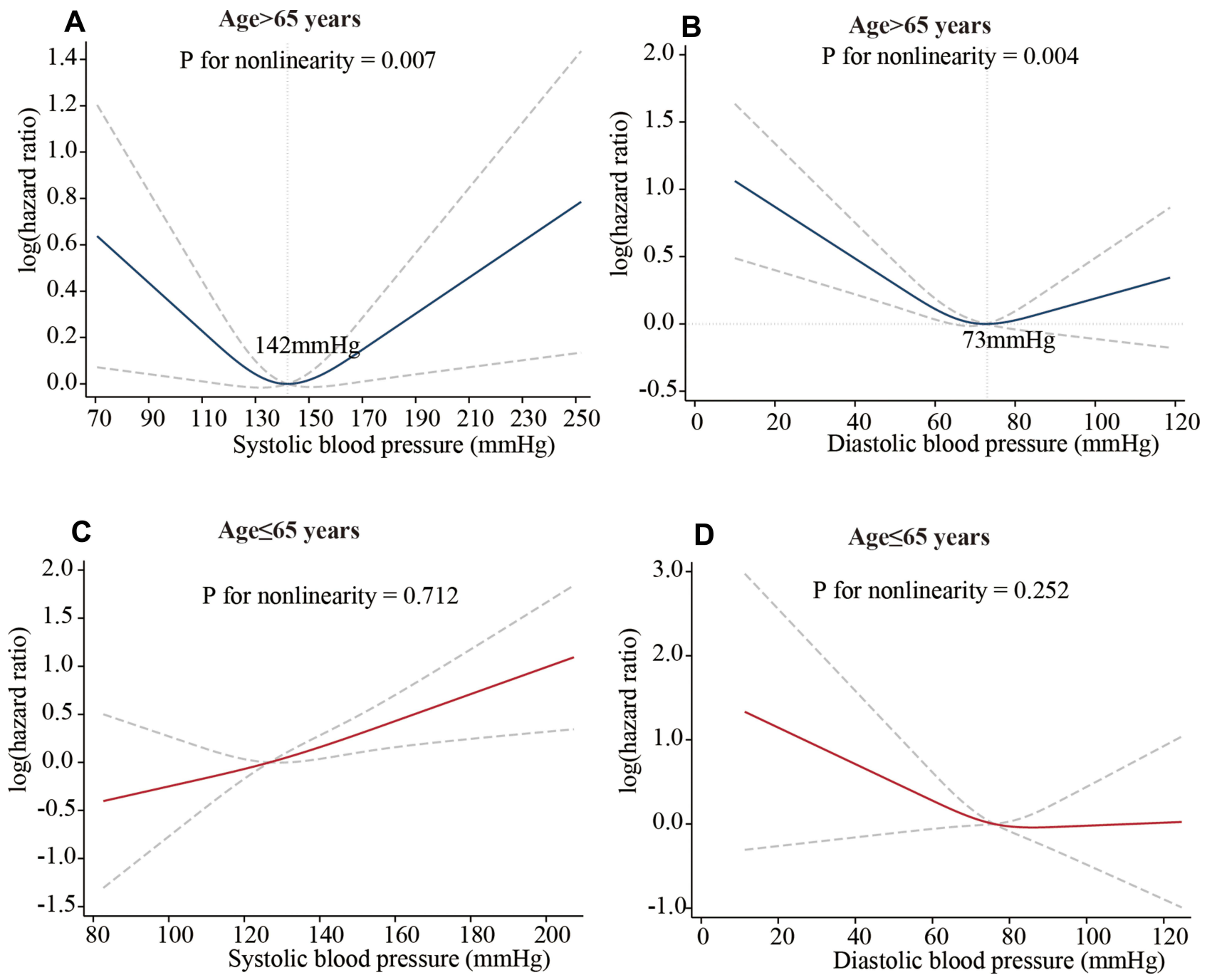

Figure 4 Restricted cubic spline plots of the association between blood pressure and all-cause mortality in different age groups. (A) SBP: age > 65 years; (B) DBP: age > 65 years; (C) SBP: age $\leq 65$ years; (D) DBP: age $\leq 65$ years. 
Table 6 Stratified Associations Between Diastolic Blood Pressure and Mortality by Age, Sex and BMI

\begin{tabular}{|c|c|c|c|c|c|c|c|}
\hline & \multirow{2}{*}{$\begin{array}{l}\mathrm{DBP} \leq 60 \mathrm{mmHg} \\
\mathrm{HR}(95 \% \mathrm{Cl})\end{array}$} & \multirow{2}{*}{$\begin{array}{l}\begin{array}{l}\mathrm{DBP}>60 \text { to } \\
\leq 70 \mathrm{mmHg}\end{array} \\
\mathrm{HR}(95 \% \mathrm{Cl})\end{array}$} & \multirow{2}{*}{$\begin{array}{l}\text { DBP>70 to } \\
\leq 80 \mathrm{mmHg}\end{array}$} & \multirow{2}{*}{$\begin{array}{l}\text { DBP>80 to } \\
\leq 90 \mathrm{mmHg}\end{array}$} & \multirow{2}{*}{$\begin{array}{l}\text { DBP>90 } \mathrm{mmHg} \\
\mathrm{HR}(95 \% \mathrm{Cl})\end{array}$} & \multicolumn{2}{|c|}{$P$ value } \\
\hline & & & & & & Trend & Interaction \\
\hline \multicolumn{8}{|l|}{ Age } \\
\hline$\leq 65, N=602$ & $1.72(0.96-3.09)$ & $0.85(0.53-1.38)$ & I.00(ref.) & $0.77(0.51-1.16)$ & $0.56(0.34-0.94)^{*}$ & 0.006 & 0.165 \\
\hline$>65, N=1094$ & $1.61(1.29-2.01)^{* * *}$ & $1.20(0.98-1.48)$ & I.00(ref.) & I.14(0.90-1.45) & $1.02(0.72-1.43)$ & $<0.001$ & \\
\hline \multicolumn{8}{|l|}{ Sex } \\
\hline Male, $\mathrm{N}=843$ & $1.43(1.07-1.89)^{*}$ & $1.06(0.82-1.37)$ & I.00(ref.) & $1.27(0.96-1.68)$ & $1.01(0.69-1.48)$ & 0.225 & 0.884 \\
\hline Female, $\mathrm{N}=853$ & $1.43(1.05-1.95)^{*}$ & $1.09(0.83-1.95)$ & 1.00 (ref.) & $1.10(0.81-1.50)$ & $1.13(0.75-1.71)$ & 0.203 & \\
\hline \multicolumn{8}{|l|}{ BMI } \\
\hline$\geq 30, N=588$ & $1.58(1.03-2.41)^{*}$ & $1.36(0.92-2.01)$ & I.00(ref.) & $1.21(0.82-1.79)$ & $1.04(0.59-1.80)$ & 0.145 & 0.534 \\
\hline$<30, N=1108$ & $1.41(1.11-1.79)^{*}$ & $0.97(0.78-1.20)$ & 1.00 (ref.) & $1.10(0.86-1.41)$ & $1.00(0.72-1.40)$ & 0.118 & \\
\hline
\end{tabular}

Notes: Analyses was adjusted for age, sex, race/ethnicity, diabetes mellitus, congestive heart failure, smoker, systolic pressure or diastolic pressure, body mass index and waist when they were not the strata variables. $* * * P<0.00 \mathrm{I}, * * P<0.0 \mathrm{I}, * P<0.05$.

Abbreviations: DBP, diastolic blood pressure; BMI, Body mass index; $\mathrm{HR}$, hazard ratios; $\mathrm{Cl}$, confidence intervals.

information on the association of all-cause mortality with elevated DBP to the available literature on this topic. Our results also highlight the optimal BP targets. In a similar study with a randomly selected cohort using the data from NHANES III, ${ }^{13}$ compared with the normal SBP group (120-140 $\mathrm{mmHg})$, the risk of all-cause mortality tended to be higher in the low-to -normal SBP group $(<120 \mathrm{mmHg})(\mathrm{HR}, 1.96 ; 95 \% \mathrm{CI}$, 1.13-3.39). Another post hoc analysis of randomized controlled trials revealed that compared with SBP between 144 and 157, an SBP $<144 \mathrm{mmHg}$ was associated with higher all-cause (HR, 1.81; 95\% CI, 1.20 2.73 ) and cardiovascular mortality (HR, 1.60; 95\% CI, 1.02-2.54). ${ }^{14}$ Both studies demonstrated a J-curve relationship between SBP and all-cause mortality.

Although in the setting of secondary stroke prevention, most previous studies have demonstrated that BP reduction has an evident benefit on stroke recurrence ${ }^{3}$ and secondary cerebral edema, ${ }^{18}$ both the optimal BP levels and the timing for achieving the BP targets after the index stroke are remain largely uncertain. SBP and DBP are closely related, and intensive treatment of SBP could also reduce DBP. Coronary perfusion occurs during the diastolic phase of the cardiac cycle, and reducing DBP could reduce diastolic perfusion pressure, resulting in myocardial ischemia, ${ }^{19,20}$ which increases the risk of cardiovascular mortality. Previous studies of coronary artery disease $\mathrm{e}^{21,22}$ and high-risk patients ${ }^{23}$ have shown a J-curve relationship of DBP with cardiovascular events. Our study was unique in reporting a reverse
J-curve relationship between DBP and all-cause mortality in stroke survivors.

Results demonstrated that there was a consistently increased risk for all-cause mortality in the hypotensive condition, particularly in older adults. One explanation for this result is that low SBP/DBP may be due to coexisting unhealthy or chronic diseases, leading to increased risk of all-cause mortality. Besides, excessive antihypertensive treatment may lead to low DBP, resulting in insufficient coronary perfusion, thus leading to coronary events. Older patients are more likely to have comorbidities such as atherosclerotic vascular disease, renal impairment, and postural hypotension, which may be worsened by antihypertensive drugs.

The association between BP and all-cause mortality has several implications for treatment strategies for stroke survivors, which might be different between elderly and relative younger patients. Current guidelines suggest a systolic value of $130-139 \mathrm{mmHg}$ and a diastolic value of $<80 \mathrm{mmHg}$ in hypertensive patients if tolerated, while treated SBP values of $<130 \mathrm{mmHg}$ should be avoided. ${ }^{7}$ Current study showed, in adults younger than 65 years, higher SBP was associated with an increased risk of mortality, while lower DBP was associated with an increased risk of mortality. While elderly stroke survivors demonstrated that a J-curve or reverse J-curve relationship between BP and all-cause mortality persists in older patients with a nadir of SBP/DBP at $142 / 73 \mathrm{mmHg}$, which is in line with current guidelines suggestion for BP reduction in older adults. Therefore, an SBP value of $140-150 \mathrm{mmHg}$, and a DBP value of $70-80 \mathrm{mmHg}$ may 
be better management target for reducing the risk of death in older adults with prior stroke.

Our study has several limitations. First, self-reported stroke was assessed in the survey, and information on stroke type, severity of stroke, functional status, treatment of stroke, drug classes, dose of medications and adherence to therapy was not available, which may play a role in the relationship between BP and all-cause mortality. Second, we only assessed baseline BP, and the effect of dynamic BP change on prognosis in stroke survivors is still unknown. Third, patients come from general populations, and selective bias cannot be avoided.

\section{Conclusion}

A J-curve or reverse J-curve relationship between BP and all-cause mortality in stroke survivors, whereas the pattern appears to be limited to individuals with an age $>65$ years, with a nadir at $142 / 73 \mathrm{mmHg}$. However, missing data on stroke type and stroke treatment limits the generalizability. Prospective studies should be further investigated. Further randomized controlled studies should establish an ideal BP goal for stroke survivors.

\section{Abbreviations}

BP, blood pressure; NHANES, National Health and Nutrition Examination Survey; SBP, systolic BP; DBP, diastolic BP; IS, ischemic stroke; TIA, transient ischemic attack; BMI, body mass index; ANOVA, analysis of variance model; HR, hazard ratio; CI, confidence interval.

\section{Acknowledgments}

We appreciate the support from the people who contributed to the NHANES data we studied. This work was supported by a National Science Foundation grant (Grant No. 81770396).

\section{Author Contributions}

All authors contributed to data analysis, drafting or revising the article, have agreed on the journal to which the article will be submitted, gave final approval of the version to be published, and agree to be accountable for all aspects of the work.

\section{Disclosure}

All authors states that there is no conflict of interest.

\section{References}

1. Virani SS, Alonso A, Benjamin EJ, et al. Heart disease and stroke statistics-2020 update: a report from the American Heart Association. Circulation. 2020;141(9):e139-e596.

2. Benjamin EJ, Muntner P, Alonso A, et al. Heart Disease and Stroke Statistics-2019 Update: A Report From the American Heart Association. Circulation. 2019;139(10):e56-e528.

3. Den Ruijter HM, Peters SA, Anderson TJ, et al. Common carotid intima-media thickness measurements in cardiovascular risk prediction: a meta-analysis. JAMA. 2012;308:796-803. doi:10.1001/jama.2012.9630

4. O'Donnell MJ, Xavier D, Liu L, et al. Risk factors for ischaemic and intracerebral haemorrhagic stroke in 22 countries (the INTERSTROKE study): a case-control study. Lancet. 2010;376 (9735):112-123. doi:10.1016/S0140-6736(10)60834-3

5. Kitagawa K, Yamamoto Y, Arima H, et al. Effect of standard vs intensive blood pressure control on the risk of recurrent stroke: a randomized clinical trial and meta-analysis. JAMA Neurol. 2019;76(11):1309. doi:10.1001/jamaneurol.2019.2167

6. Whelton PK, Carey RM, Aronow WS, et al. 2017 ACC/AHA/AAPA/ $\mathrm{ABC} / \mathrm{ACPM} / \mathrm{AGS} / \mathrm{APhA} / \mathrm{ASH} / \mathrm{ASPC} / \mathrm{NMA} / \mathrm{PCNA}$ guideline for the prevention, detection, evaluation, and management of high blood pressure in adults: executive summary: a report of the American College of Cardiology/American Heart Association Task Force on Clinical Practice Guidelines. Hypertension. 2018;71(6):1269-1324.

7. Williams B, Mancia G, Spiering W, et al. 2018 ESC/ESH guidelines for the management of arterial hypertension. Eur Heart J. 2018;39 (33):3021-3104

8. Katsanos AH, Filippatou A, Manios E, et al. Blood pressure reduction and secondary stroke prevention: a systematic review and metaregression analysis of randomized clinical trials. Hypertension. 2017;69(1):171-179. doi:10.1161/HYPERTENSIONAHA.116.08485

9. Ovbiagele B. Low-normal systolic blood pressure and secondary stroke risk. J Stroke Cerebrovasc Dis. 2013;22(5):633-638. doi:10.1016/j.jstrokecerebrovasdis.2011.12.003

10. Ovbiagele B, Diener HC, Yusuf S, et al. Level of systolic blood pressure within the normal range and risk of recurrent stroke. JAMA. 2011;306(19):2137-2144. doi:10.1001/jama.2011.1650

11. Xie X, Xu J, Gu H, et al. The J-curve association between systolic blood pressure and clinical outcomes in ischemic stroke or TIA: the BOSS Study. Sci Rep. 2017;7(1):14023. doi:10.1038/s41598-01710887-w

12. Irie K, Yamaguchi T, Minematsu K, et al. The J-curve phenomenon in stroke recurrence. Stroke. 1993;24(12):1844-1849. doi:10.1161/01. STR.24.12.1844

13. Lin MP, Ovbiagele B, Markovic D, et al. Systolic blood pressure and mortality after stroke: too low, no go? Stroke. 2015;46(5):1307-1313. doi:10.1161/STROKEAHA.115.008821

14. Okin PM, Kjeldsen SE, Devereux RB. Systolic blood pressure control and mortality after stroke in hypertensive patients. Stroke. 2015;46(8):2113-2118. doi:10.1161/STROKEAHA.115.009592

15. Flegal KM, Kruszon-Moran D, Carroll MD, et al. Trends in obesity among adults in the United States, 2005 to 2014. JAMA. 2016;315 (21):2284-2291. doi:10.1001/jama.2016.6458

16. Chen X, Wei G, Jalili T, et al. The associations of plant protein intake with all-cause mortality in CKD. Am J Kidney Dis. 2016;67 (3):423-430. doi:10.1053/j.ajkd.2015.10.018

17. Desquilbet L, Mariotti F. Dose-response analyses using restricted cubic spline functions in public health research. Stat Med. 2010;29 (9):1037-1057.

18. Sprigg N, Gray LJ, Bath PMW, et al. Relationship between outcome and baseline blood pressure and other haemodynamic measures in acute ischaemic stroke: data from the TAIST trial. J Hypertens. 2006;24(7):1413-8. doi:10.1097/01.hjh.0000234123.55895.12 
19. Chrysant SG. New evidence for the diastolic J-curve effect challenges the safety of intensive blood pressure control. J Clin Hypertens. 2017;19(4):340-343. doi:10.1111/jch.12962

20. McEvoy JW, Chen Y, Rawlings A, et al. Diastolic blood pressure, subclinical myocardial damage, and cardiac events: implications for blood pressure control. J Am Coll Cardiol. 2016;68(16):1713-1722. doi:10.1016/j.jacc.2016.07.754

21. Messerli FH, Mancia G, Conti CR, et al. Dogma disputed: can aggressively lowering blood pressure in hypertensive patients with coronary artery disease be dangerous? Ann Intern Med. 2006;144(12):884-893. doi:10.7326/0003-4819-144-12-20060620 $0-00005$
22. Franklin SS, Gokhale SS, Chow VH, et al. Does low diastolic blood pressure contribute to the risk of recurrent hypertensive cardiovascular disease events? The Framingham Heart Study. Hypertension. 2015;65(2):299-305. doi:10.1161/HYPERTENSIONAHA.114.04 581

23. Bohm M, Schumacher H, Teo KK, et al. Achieved blood pressure and cardiovascular outcomes in high-risk patients: results from ONTARGET and TRANSCEND trials. Lancet. 2017;389(100 85):2226-2237. doi:10.1016/S0140-6736(17)30754-7

\section{Publish your work in this journal}

The International Journal of General Medicine is an international, peer-reviewed open-access journal that focuses on general and internal medicine, pathogenesis, epidemiology, diagnosis, monitoring and treatment protocols. The journal is characterized by the rapid reporting of reviews, original research and clinical studies across all disease areas. The manuscript management system is completely online and includes a very quick and fair peer-review system, which is all easy to use. Visit http://www.dovepress.com/ testimonials.php to read real quotes from published authors.

Submit your manuscript here: https://www.dovepress.com/international-journal-of-general-medicine-journal 